\title{
El Tribunal Constitucional del Perú y la actual aplicación de su función sancionadora en materia disciplinaria: análisis de resoluciones que imponen multas a abogados
}

\author{
O Tribunal Constitucional do Peru e a aplicação atual de sua função sancionadora \\ em matéria disciplinar: análise das resoluções que impõem multas a advogados
}

\section{The Constitutional Court of Peru and current application of its sanctioning function in disciplinary matter: analysis of resolutions imposing fines on lawyers}

\author{
Renato Constantino Caycho \\ Sofía Rodríguez Yupanqui* \\ Teresa Arce Coronel ${ }^{* \star}$ \\ Alejandro Cisneros Mincher ${ }^{\star \star \star *}$ \\ Angélica Angulo Remuzgo
}

\section{Resumen}

En Perú, la negligencia profesional del abogado puede ser sancionada por distintos órganos del Estado, entre ellos, el Tribunal Constitucional. Sin haber regulación del trámite a ser seguido por los magistrados de este tribunal para sancionar a los abogados, este trabajo analiza una serie de resoluciones de este órgano jurisdiccional por las cuales estos profesionales fueron sancionados para encontrar puntos comunes. Así, después de revisar las deliberaciones seleccionadas, se sigue con el análisis para (i) determinar la base normativa la cual son sancionados los abogados; (ii) identificar los criterios adoptados actualmente por este tribunal para sancionar las faltas cometidas por estos profesionales; $y$, (iii) identificar posibles errores en el procedimiento, de los cuales enfocamos el posible incumplimiento de garantías procesales como el non bis in idem. Asimismo, son hechas, al final del texto, algunas recomendaciones en relación a las debilidades encontradas.

Palabras-clave: Abogados. Sanciones. Tribunal Constitucional. Criterios. Garantías procesales.

\section{Resumo}

No Peru, a negligência profissional do advogado pode ser sancionada por diversos órgãos do Estado, entre eles, o Tribunal Constitucional. Não havendo regulamentação do procedimento os quais os magistrados desse tribunal devem seguir para punir os advogados, este texto analisa uma série de resoluções de tal órgão jurisdicional por meio das quais esses profissionais foram sancionados para encontrar pontos em comum. Assim, após a revisão das deliberações selecionadas, procede-se à referida análise para: (i) determinar a base normativa sobre a qual os advogados são sancionados; (ii) identificar os critérios que este tribunal utiliza atualmente para punir as infrações cometidas pelos referidos profissionais; e (iii) identificar possiveis falhas no procedimento, dentre as quais se destaca a possivel inobservância de garantias processuais como non bis in idem. Da mesma forma, no final do texto são feitas algumas recomendações em relação às lacunas encontradas.

Palavras-chave: Advogados. Sanções Corte Constitucional. Critério. Garantias processuais.

Magíster y abogado y en derechos humanos por la Pontificia Universidad Católica del Perú (PUCP), Perú. LLM en International Legal Studies por American University Washington College of Law. Docente del Departamento de Derecho de la PUCP. Correo: renato.constantino@pucp.pe

(iD) Abogada por la Pontificia Universidad Católica del Perú, (PUCP), Perú. Con Segunda Especialidad en Derechos Fundamentales y Constitucionalismo en América Latina por la Pontificia Universidad Católica del Perú, (PUCP), Perú. Adjunta de docencia del curso Derechos Fundamentales y Justicia Constitucional en el Programa de Segunda Especialidad de Derechos Fundamentales y Constitucionalismo en América Latina de la misma casa de estudios. Correo: sofia.rodriguezy@pucp.pe

**- (iD Egresada de la Facultad de Derecho de la Pontificia Universidad Católica del Perú, (PUCP), Perú. Adjunta de docencia de los cursos No Discriminación y Derecho y Clínica Jurídica de la misma casa de estudios. Correo: t.arce@pucp.pe

.... (D) Bachiller de Derecho por la Pontificia Universidad Católica del Perú (PUCP). Correo: cisneros.a@pucp.pe

..... (iD Bachiller de Derecho por la Pontificia Universidad Católica del Perú (PUCP), Perú. Asociada del Círculo de Derecho Administrativo, miembro de la Comisión de Publicaciones. Correo: a20160293@pucp.edu.pe

El presente artículo está basado en un informe elaborado por los primeros cuatro autores en el marco del programa de Voluntariado de la

Facultad de Derecho de la PUCP. Se agradece al abogado Óscar Alejos por sus comentarios y sugerencias. 


\begin{abstract}
In Peru, the bad professional practice of the lawyer is liable to be sanctioned by different organs of the State, among them, the Constitutional Court. Thus, there is no regulation of the procedure which the magistrates of this court must follow to punish the lawyers, this text analyzes some resolutions of this jurisdictional court through which theses professionals were sanctioned to find common points. Thus, after reviewing the selected resolutions, the aforementioned analysis is carried out to (i) determine the normative basis on which lawyers are sanctioned; (ii) to identify the criteria that this court currently uses to punish the offenses committed by these professionals; and (iii) to identify possible deficiencies or problems in the procedure, including the possible non-observance of procedural guarantees such as non bis in idem. Likewise, at the end of the text, some recommendations are raised concerning the shortcomings found.
\end{abstract}

Keywords: Lawyers. Penalties. Constitutional Court of Perú. Criteria. Procedural guarantees.

\title{
1 Introducción
}

El artículo 3 del Código de Ética del Abogado señala que "la abogacía tiene por fin la defensa de los derechos de las personas y la consolidación del Estado de Derecho, la justicia y el orden social (...)"1. En ese sentido, un abogado es un colaborador de la administración de justicia, cumple una función social que lo hace merecedor de un tratamiento legal más exigente (RAMÍREZ, 2015). Así, su accionar se encuentra direccionado y regulado por diferentes cuerpos normativos tales como el Código de Ética del Abogado, el Código Procesal Civil², el Código Procesal Penal ${ }^{3}$, entre otros, y el incumplimiento de tales mandatos, por supuesto, está sujeto al ius puniendi del Estado.

En el Perú, son múltiples los órganos que tienen la potestad de hacer uso de ese ius puniendi y de sancionar a los abogados por mala práctica profesional, entre ellos, los Colegios de Abogados, juzgados, y también, el Tribunal Constitucional ("TC"). En tanto son órganos de distinta naturaleza, los procedimientos establecidos para sancionar a los abogados también son diferentes. Estos pueden ser jurisdiccionales, disciplinarios y/o administrativos.

En el presente texto se estudiará el actuar del Tribunal Constitucional en materia disciplinaria. Para ello, se analizarán cinco resoluciones sancionatorias emitidas por este órgano ("los casos seleccionados") con el fin de (i) determinar la base normativa sobre la cual se sanciona a los abogados; (ii) identificar los criterios que se toma en cuenta para sancionar a dichos profesionales por mala praxis; e, (iii) identificar posibles falencias del procedimiento y plantear algunas recomendaciones.

En concordancia con el Texto Único Ordenado (TUO) de la Ley Orgánica del Poder Judicial. Artículo 288.1. "Son deberes del Abogado Patrocinante: Actuar como servidor de la Justicia y como colaborador de los Magistrados".

Y con el TUO del Código Procesal Civil. Artículo 109.1. "Son deberes de las partes, Abogados y apoderados:

1. Proceder con veracidad, probidad, lealtad y buena fe en todos sus actos e intervenciones en el proceso (...)".

2 Artículo 109.- Son deberes de las partes, Abogados y apoderados:

"1. Proceder con veracidad, probidad, lealtad y buena fe en todos sus actos e intervenciones en el proceso;

2. No actuar temerariamente en el ejercicio de sus derechos procesales;

3. Abstenerse de usar expresiones descomedidas o agraviantes en sus intervenciones;

4. Guardar el debido respeto al Juez, a las partes y a los auxiliares de justicia;

5. Concurrir ante el Juez cuando este los cite y acatar sus órdenes en las actuaciones judiciales; $y$

6. Prestar al Juez su diligente colaboración para las actuaciones procesales, bajo apercibimiento de ser sancionados por inconducta con una multa no menor de tres ni mayor de cinco Unidades de Referencia Procesal".

3 Artículo 84. Derechos y deberes del abogado defensor

"El abogado defensor goza de todos los derechos que la ley le confiere para el ejercicio de su profesión, especialmente de los siguientes:(...) 9. Expresarse con amplia libertad en el curso de la defensa, oralmente y por escrito, siempre que no se ofenda el honor de las personas, ya sean naturales o jurídicas. 10. (...) El abogado defensor está prohibido de recurrir al uso de mecanismos dilatorios que entorpezcan el correcto funcionamiento de la administración de justicia."

Artículo 85. Reemplazo del abogado defensor inasistente

“(...) 3. El juez o colegiado competente sanciona, de conformidad con el artículo $292^{\circ}$ de la Ley Orgánica del Poder Judicial, al abogado defensor que injustificadamente no asiste a una diligencia a la que ha sido citado o que injustificadamente abandona la diligencia que se estuviere desarrollando.

(...) 5. Las sanciones son comunicadas a la Presidencia de la Corte Superior y al Colegio de Abogados del Distrito Judicial respectivo. La primera conoce la aplicación de la sanción y el segundo la ejecución formal de la sanción" (énfasis agregado). Se debe resaltar que el Nuevo Código Procesal Penal establece como órgano ejecutor de la sanción al Colegio de Abogados del Distrito Judicial, como si la conducta procesal sancionada tuviese la misma naturaleza que la conducta ética supervisada por los Colegios Profesionales de Abogados. 


\section{Los casos seleccionados}

Las cinco resoluciones objeto de análisis del presente texto fueron extraídas del Registro Nacional de Abogados Sancionados (en adelante, "RNAS"), el cual registra información hasta por cinco años de las sanciones vigentes o vencidas, conforme con el Decreto Legislativo $1265^{4}$. La data acerca de los casos resueltos por el Tribunal Constitucional sobre la materia, no es muy abundante en el RNAS, por lo que incluimos todos aquellos casos que habían sido registrados hasta el $2020^{5}$. Es de añadir que elegimos el Tribunal Constitucional por su importancia como referente en la interpretación de las normas, y una de las instituciones más importantes en nuestro país.

En cada una de las resoluciones, cuyos datos han sido resumidos en la Tabla 1, el Tribunal Constitucional emitió su fallo y sancionó a los abogados, pero también ordenó la remisión de lo actuado a otras instancias. Tal remisión fue efectuada con objeto de que dichas entidades procedieran de conformidad con sus atribuciones. Así, por ejemplo, sancionando al implicado al determinar la configuración de algún ilícito penal o en atención a alguna infracción de las reglas de buen comportamiento de un abogado con base en su Código de Ética. El único caso en el que el Tribunal no realizó dicha remisión fue en el recaído en el Expediente N. ${ }^{\circ}$ 4021-2014-PA/TC. Esto, debido a que la falta se limitó a dicha instancia (inclusión de frases vejatorias contra los magistrados en el escrito).

Tabla 1: Resoluciones seleccionadas del RNAS

\begin{tabular}{|c|c|c|c|c|}
\hline $\begin{array}{l}\text { Número y fecha } \\
\text { de Resolución }\end{array}$ & $\begin{array}{l}\text { Nombre del } \\
\text { abogado }\end{array}$ & Falta & $\begin{array}{l}\text { Tipo de } \\
\text { sanción }\end{array}$ & Se remitió el caso a \\
\hline $\begin{array}{l}\text { EXP. N¹89- } \\
2016-P A / T C \\
11 / 09 / 2018\end{array}$ & $\begin{array}{l}\text { Helmer Elide } \\
\text { Fernández Hurtado }\end{array}$ & $\begin{array}{l}\text { Falsificación de } \\
\text { documentos }\end{array}$ & Multa 10 URP & $\begin{array}{l}\text { - Corte Superior de Justicia de Ica } \\
\text { - Colegio de Abogados de Ica } \\
\text { - Colegio de Notarios de Ica } \\
\text { - Fiscal provincial penal de turno }\end{array}$ \\
\hline $\begin{array}{l}\text { EXP. N4241- } \\
2014-P A / T C \\
12 / 11 / 2018\end{array}$ & $\begin{array}{l}\text { Rosa Mary Aparcana } \\
\text { Vega y Víctor Daniel } \\
\text { Huamán Ramos }\end{array}$ & $\begin{array}{l}\text { Falsificación de } \\
\text { documentos }\end{array}$ & $\begin{array}{l}\text { Multa } 10 \text { URP } \\
\text { (cada uno) }\end{array}$ & $\begin{array}{l}\text { - Presidencia de la Corte Superior de Justicia } \\
\text { de Ica } \\
\text { - Colegio de Abogados de Ica } \\
\text { - Consejo del Notariado } \\
\text { - Colegio de Notarios } \\
\text { - Fiscal provincial penal de tumo }\end{array}$ \\
\hline $\begin{array}{l}\text { EXP. N5030- } \\
2015-P A / T C \\
03 / 12 / 2017\end{array}$ & $\begin{array}{l}\text { Cesar Augusto } \\
\text { Ramírez Valdez }\end{array}$ & $\begin{array}{l}\text { Falsificación de } \\
\text { documentos }\end{array}$ & Multa 10 URP & $\begin{array}{l}\text { - Presidencia de la Corte Superior de Justicia } \\
\text { de La Libertad } \\
\text { - Colegio de Abogados de La Libertad } \\
\text { - Fiscal provincial penal de turno }\end{array}$ \\
\hline $\begin{array}{l}\text { EXP. N7818- } \\
2013-P A / T C \\
09 / 05 / 2017\end{array}$ & $\begin{array}{l}\text { Juan José Donayre } \\
\text { Mendoza }\end{array}$ & $\begin{array}{l}\text { Falsificación de } \\
\text { documentos }\end{array}$ & $\begin{array}{l}\text { Multa } 10 \text { URP } \\
\text { (solidaria) }\end{array}$ & $\begin{array}{l}\text { - Corte Superior de Justicia de Ica } \\
\text { - Colegio de Abogados de Ica } \\
\text { - Fiscal provincial de turno } \\
\text { - Consejo de Notariado }\end{array}$ \\
\hline $\begin{array}{l}\text { EXP. N }{ }^{\circ} 4021- \\
2014-P A / T C \\
28 / 03 / 2017\end{array}$ & $\begin{array}{l}\text { Walter Iván López } \\
\text { Pérez }\end{array}$ & $\begin{array}{l}\text { Frases } \\
\text { vejatorias hacia } \\
\text { magistrados }\end{array}$ & Multa 10 URP & No se remitió el caso a ninguna entidad \\
\hline
\end{tabular}

\subsection{Un breve recuento de los hechos de los casos seleccionados ${ }^{6}$}

\section{i. Exp. N. ${ }^{\circ}$ 189-2016-PA/TC (Anonimizado). Abogado sancionado: Helmer Fernández Hurtado}

El primer caso, Caso Fernández, ${ }^{7}$ fue resuelto por los magistrados Ramos Núñez, Ledesma Narváez y Espinosa-Saldaña Barrera, mediante sentencia interlocutoria denegatoria ${ }^{8}$, bajo la causal de contravención de un precedente del Tribunal Constitucional.

El demandante pretendía que se le otorgue una pensión, conforme al Decreto Ley 19990, por la totalidad de las aportaciones que había realizado, alegando que la Oficina de Normalización Previsional (“ONP”) le había

Vigente desde el 16 de diciembre de 2016.

5 Cabe añadir que las resoluciones seleccionadas fueron emitidas entre 2017 y 2019 , por lo que se encuentran dentro del periodo de los últimos cinco años, límite de tiempo que se ajusta a lo establecido por la Ley de Protección de Datos Personales.

6 En el presente informe no se consignará el nombre de los demandantes, debido a que las resoluciones están anonimizadas en el RNAS. Sin embargo, no sería ilegal registrarlos, en cuanto se trata de información de carácter público.

7 Con el fin de identificar más fácilmente los casos seleccionados, nos referiremos a ellos por el primer apellido de los abogados sancionados.

8 Figura creada por el Tribunal Constitucional mediante la sentencia recaída en el Expediente N ${ }^{\circ}$ 987-2014-PA/TC, precedente de observancia obligatoria. A través de esta figura se termina el proceso declarando su improcedencia. 
reconocido una menor cantidad de las que en realidad había efectuado. El recurrente señaló que sólo se le habían reconocido 6 años de aportes e intentó acreditar una mayor cantidad de aportaciones presentando más certificados de trabajo. Así, presentó un certificado de trabajo y una liquidación de beneficios sociales, pero los jueces observaron que las firmas de documentos provenientes de diferentes empresas eran totalmente idénticas, por lo cual, se presumió una posible falsificación de documentos.

El Departamento de Grafotecnia de la Policía Nacional del Perú emitió una pericia en la cual señaló que los documentos eran fraudulentos. Por otro lado, el Tribunal estimó que las fechas en las cuales el demandante dijo haber laborado en el campo eran manifiestamente inverosímiles, pues en los documentos consignados figuraba que inició actividades el 2 de enero de 1957, es decir, cuando tenía 9 años.

ii. Exp. N. ${ }^{0}$ 4241-2014-PA/TC (Anonimizado). Abogados sancionados: Rosa Mary Aparcana Vega y Víctor Manuel Huamán Ramos

El segundo caso, el Caso Aparcana - Huamán, fue resuelto por los magistrados Miranda Canales, Sardón de Taboada y con la participación del magistrado Espinosa-Saldaña Barrera, llamado a dirimir por el voto singular del magistrado Ferrero Costa. Fue resuelto mediante sentencia interlocutoria denegatoria, bajo la causal de que ya se ha decidido de manera desestimatoria en casos sustancialmente iguales.

La recurrente solicitó desafiliarse del Sistema Privado de Pensiones y acceder a una pensión al amparo del Decreto Ley 19990. Tal solicitud fue denegada por la ONP en tanto, de acuerdo con su Reporte Situacional para Desafiliación, no se le reconocían aportaciones. A fin de acreditarlas, la recurrente presentó documentación con objeto de demostrar haber realizado labores en las empresas: Tiendas Industriales Asociadas S.A., Distribuidora del Sur S.A., Cooperativa Agraria de Producción Cerro Blanco y Unanue Ltda., así como en el Comité Especial de Administración de los Valles de Nazca y Palpa. El Tribunal observó que, tanto en los certificados de trabajo como en las liquidaciones de beneficios sociales las firmas eran idénticas, lo que generó la presunción acerca de la falsedad de los documentos; presunción que luego fue confirmada por una pericia grafotécnica de la PNP.

iii. Exp. N. ${ }^{\circ}$ 5030-2015-PA/TC (Anonimizado). Abogado sancionado: César Augusto Ramírez Valdez

El tercer caso, el Caso Ramírez, fue resuelto por los magistrados Urviola Hani, Ramos Nuñez y EspinosaSaldaña Barrera mediante sentencia interlocutoria denegatoria, en tanto la cuestión de derecho invocada por el demandante contravenía un precedente del Tribunal Constitucional.

En este caso, la recurrente solicitó que se le otorgue una pensión de jubilación anticipada conforme al Decreto Ley 19990. Para ello, presentó documentos con la intención de acreditar su pretensión. Estos fueron valorados por el Tribunal que consideró la documentación presentada como no idónea. Se identificaron varias incongruencias: documentos de empresas que no existían, boletas de pago con códigos equivocados, un documento de liquidación con el documento de identidad mal escrito e, incluso, un documento de una sociedad anónima cerrada de un momento previo a la existencia de dicha figura en el ordenamiento jurídico peruano.

iv. Exp. N. ${ }^{\circ} 7818-2013-P A / T C$ (Anonimizado). Abogado sancionado: Juan José Donayre Mendoza

El cuarto caso, el Caso Donayre, estuvo a cargo de los magistrados Ledesma Narváez, Sardón de Taboada y contó con la participación del magistrado Espinosa-Saldaña Barrera, pero se tuvo que recurrir al magistrado Blume Fortini para dirimir la controversia. El caso fue resuelto mediante sentencia interlocutoria denegatoria emitida por resolución de fecha 9 de mayo de 2017. Dicho fallo, al igual que en el caso anterior, se debió a que la cuestión de derecho invocada por el demandante contravenía un precedente del Tribunal.

El demandante solicitó el otorgamiento de una pensión del régimen general de jubilación con base en el Decreto Ley 19990, para el cual, a partir de la entrada en vigencia del Decreto Ley 25967, se requiere haber efectuado aportaciones por un mínimo de 20 años. El Tribunal indicó que el demandante no había cumplido con adjuntar los documentos para acreditar sus aportaciones a la ONP y acceder a la pensión que solicitaba. El certificado de trabajo ofrecido para acreditar una relación laboral había sido suscrito por el contador de la entidad, sujeto que no tenía facultades al respecto. Asimismo, respecto de la Constancia de Aportaciones emitida por la Gerencia General de Prestaciones de ESSALUD, el TC solicitó información a dicha institución, la cual negó la veracidad del informe.

v. Exp. N. ${ }^{\circ}$ 4021-2014-PA/TC (Anonimizado). Abogado sancionado: Walter Iván López Pérez

El quinto caso, el Caso López, fue declarado improcedente por los magistrados Ledesma Narváez, Ramos Núñez y Espinosa-Saldaña Barrera, mediante resolución de fecha 28 de marzo de 2017. En el escrito presentado por la demandante, y que fue suscrito por su abogado, se observó la inclusión de frases vejatorias y ofensivas dirigidas hacia los magistrados, las que se leen a continuación: 
TODOS LOS DENUNCIADOS Y LOS MAGISTRADOS DEL TRIBUNAL CONSTITUCIONAL ENCABEZADOS POR el delictuoso magistrado OSCAR URVIOLA HANI, asumiendo la responsabilidad civil y penal tienen que ser destituidos conforme lo establece la legislación del sistema anticorrupción y de ratificación de la muerte civil a funcionarios corruptos o para que con inhabilitación absoluta sean enviados a la cárcel (...).

(...) [L]os tres magistrados del Tribunal Constitucional, Marianella Leonor Ledesma Narváez, Carlos Augusto Ramos Núñez, y Eloy Andrés Espinosa-Saldaña Barrera, direccionados, manipulados, y dirigidos por el magistrado Oscar Urviola Hani, han vuelto a expedir la Resolución del 2-9-2016 (...) falseando, adulterando y falsificando el sentido de las leyes (...) (fundamento 5). (Énfasis agregado).

El Tribunal consideró que las citadas frases eran incompatibles con una conducta procesal correspondiente "al respeto y a la importancia propias de la actividad jurisdiccional" (fundamento 6), y en razón de ello, impuso una sanción a la demandante y a su abogado. Al mismo tiempo, se declaró improcedente el recurso interpuesto debido a la inobservancia de las normas procesales en que se había incurrido.

\section{Potestad del Tribunal Constitucional para sancionar a abogados}

El Código Procesal Constitucional, mediante sus artículos $56^{9}$ y $97^{10}$, otorga la potestad al juez de condenar al demandante, en caso se desestime el amparo o la acción popular, al pago de costas y costos (únicamente costos en el caso de acción popular) cuando estime que incurrió en manifiesta temeridad. "Si bien la potestad es respecto de los demandantes, el TC la ha ejercido para sancionar a sus abogados” (VARGAS, 2019, p. 2014).

Por otro lado, el artículo 49 del Reglamento Normativo del Tribunal Constitucional otorga la potestad al TC de imponer multas a cualquier persona cuando contravenga el artículo 109 del Código Procesal Civil:

Gratuidad del procedimiento. Multas

Artículo 49.- El procedimiento ante el Tribunal Constitucional es gratuito. No obstante, cuando se solicitan copias certificadas, el costo es de cargo del solicitante.

El Tribunal puede imponer multas a cualquier persona, investida o no de función pública, que incumpla los requerimientos de comportarse con sujeción a lo dispuesto en el artículo 109 del Código Procesal Civil.

Las multas pueden ser de 10 a 50 Unidades de Referencia Procesal. Lo recabado por concepto de multas constituye recursos propios del Tribunal Constitucional. (Énfasis agregado).

Es en esta norma que se fundamentan todas las multas interpuestas en las resoluciones materia de análisis del presente texto. En ese sentido, cabe realizar algunas observaciones relativas al citado artículo.

En primer lugar, establece que el Tribunal Constitucional puede imponer multas a cualquier persona, investida o no de función pública. Esto se evidencia en las resoluciones materia de análisis, por cuanto no solamente se sancionó al abogado defensor, sino también a su patrocinado. Ejercer la función pública, entonces, no es un requisito que deba verificarse a fin de que el Tribunal imponga una sanción. Por el contrario, el máximo intérprete de la Constitución se encuentra facultado para sancionar tanto a los abogados como a las personas naturales o representantes de las personas jurídicas que participen del proceso, siempre que incurran en las causales establecidas.

9 Artículo 56.- Costas y costos.- "Si la sentencia declara fundada la demanda, se impondrán las costas y costos que el Juez establezca a la autoridad, funcionario o persona demandada. Si el amparo fuere desestimado por el Juez, éste podrá condenar al demandante al pago de costas y costos cuando estime que incurrió en manifiesta temeridad. En los procesos constitucionales el Estado sólo puede ser condenado al pago de costos. (...)".

10 Artículo 97.- Costos.- "Si la sentencia declara fundada la demanda se impondrán los costos que el juez establezca, los cuales serán asumidos por el Estado. Si la demanda fuere desestimada por el Juez, éste podrá condenar al demandante al pago de los costos cuando estime que incurrió en manifiesta temeridad. (...)". 
En segundo lugar, el Tribunal Constitucional sanciona con base en el incumplimiento de los requerimientos de comportamiento regulados en el artículo 109 del Código Procesal Civil ${ }^{11}$. Es así que, la potestad sancionadora del Tribunal se encuentra fundamentada en su Reglamento, el cual, a su vez, hace una remisión expresa al Código Procesal Civil, sin dejar de considerar que el Código Procesal Penal también prevé sanciones en el mismo sentido. Dicha potestad se despliega en aquellos supuestos en los que se aprecia una inconducta por parte de los abogados y las partes en el proceso, faltando a sus deberes y responsabilidades en el marco del mismo; deberes que pueden ser entendidos en su conjunto como deber de buena fe procesal (SEVILLA, 2016, p. 633). Es en razón de esta falta que el Tribunal se pronuncia dictando la sanción legal correspondiente.

En tercer lugar, en cuanto a las sanciones que el Tribunal Constitucional puede imponer en virtud del artículo 49 de su Reglamento, estas pueden ser únicamente multas de entre 10 y 50 Unidades de Referencia Procesal $(\mathrm{URP})^{12}$. Es posible identificar que la sanción resulta más gravosa en comparación con la que se dispone en el artículo 109 del Código Procesal Civil anteriormente citado, sanción que fluctúa entre 3 y 5 URP. En los casos analizados en el presente texto, se aprecia que se ha impuesto en todos ellos el monto mínimo de multa a los abogados, esto es, 10 URP.

\section{Análisis de los casos}

El Tribunal señaló en los tres primeros casos, Fernández, Aparcana - Huamán, y Ramírez, que tanto los recurrentes como sus abogados habrían incurrido en actos temerarios, de acuerdo con lo dispuesto por el numeral 2 del artículo 109 del Código Procesal Civil ${ }^{13}$. Tal artículo prescribe como un deber de las partes, abogados y apoderados, el no actuar temerariamente en el ejercicio de sus derechos procesales. De esto se desprende que, para el Tribunal Constitucional, el "actuar temerario" se identifica con la presentación de documentos fraudulentos al interior del proceso, mediante los cuales se pretende sorprender al Tribunal; a ello alude también el inciso 2 del artículo 112 del Código Procesal Civil ${ }^{14}$.

Al respecto, el mencionado artículo $112^{15}$, que describe los casos en los cuales se determina la actuación con temeridad o mala fe de los partícipes en el proceso, es citado en los tres casos señalados. En dichas resoluciones no se hace referencia a algún inciso en particular, pero la mención del artículo permite presuponer que la conducta de las partes, de acuerdo a la interpretación del Tribunal, se identifica con una actuación temeraria o de mala fe, que es además reiterada, tal como se precisa en las resoluciones. Cabe resaltar que, a pesar de que en la doctrina

11 Artículo 109.- Son deberes de las partes, Abogados y apoderados:

"1. Proceder con veracidad, probidad, lealtad y buena fe en todos sus actos e intervenciones en el proceso;

2. No actuar temerariamente en el ejercicio de sus derechos procesales;

3. Abstenerse de usar expresiones descomedidas o agraviantes en sus intervenciones;

4. Guardar el debido respeto al Juez, a las partes y a los auxiliares de justicia;

5. Concurrir ante el Juez cuando este los cite y acatar sus órdenes en las actuaciones judiciales; y

6. Prestar al Juez su diligente colaboración para las actuaciones procesales, bajo apercibimiento de ser sancionados por inconducta con una multa no menor de tres ni mayor de cinco Unidades de Referencia Procesal".

12 La URP es una figura dispuesta por la Ley Orgánica del Poder Judicial y utilizada para la fijación de las cuantías, tasas, aranceles y multas previstas en dicha Ley o establecidas en legislación procesal especial. Su valor es fijado anualmente por el Poder Judicial. De acuerdo con la Resolución Administrativa $\mathrm{N}^{\circ}$ 393-2020-CE-PJ, el valor actual de la URP es de S/440, aproximadamente US\$121.1 de acuerdo al cambio promedio del Banco Central de Reserva del Perú al 16 de abril de 2021. El valor de la URP ha tenido un incremento de S/ 35 soles desde el 2017 , año en el que su valor era de S/ 405, de acuerdo con la Resolución Administrativa Nº11-2017-CE-PJ.

13 Artículo 109.- "Son deberes de las partes, Abogados y apoderados.

(...) 2. No actuar temerariamente en el ejercicio de sus derechos procesales".

14 Artículo 112.- "Se considera que ha existido temeridad o mala fe en los siguientes casos: (...) 2. Cuando a sabiendas se aleguen hechos contrarios a la realidad".

15 Temeridad o mala fe.- Artículo 112.- "Se considera que ha existido temeridad o mala fe en los siguientes casos:

1. Cuando sea manifiesta la carencia de fundamento jurídico de la demanda, contestación o medio impugnatorio;

2. Cuando a sabiendas se aleguen hechos contrarios a la realidad;

3. Cuando se sustrae, mutile o inutilice alguna parte del expediente;

4. Cuando se utilice el proceso o acto procesal para fines claramente ilegales o con propósitos dolosos o fraudulentos:

5. Cuando se obstruya la actuación de medios probatorios; y

6. Cuando por cualquier medio se entorpezca reiteradamente el desarrollo normal del proceso;

7. Cuando por razones injustificadas las partes no asisten a la audiencia generando dilación" 
se distingue entre temeridad y mala fe procesal (PALACIOS, 2016. p. 657), el Tribunal Constitucional, al igual que el Código Procesal Civil, se refiere a ellas como si se tratase de una misma y única figura ${ }^{16}$.

Por otra parte, en los tres casos aludidos, se menciona que se aplica también de manera supletoria el artículo IV del Título Preliminar del Código Procesal Civil ${ }^{17}$. Con dicho artículo se reitera de modo general lo que señala el artículo 109 del mismo cuerpo normativo, al indicar que las partes, sus representantes, sus abogados y, en sí, todos los partícipes en el proceso, tienen el deber de adecuar su conducta al cumplimiento de los deberes de veracidad, probidad, lealtad y buena fe. De tal modo, se establece un ideal de conducta procesal que debe seguirse al interior del proceso, y cuya inobservancia es reprendida por el ordenamiento jurídico. Al mismo tiempo, el artículo IV, reafirma la potestad sancionadora del juez, indicando que este tiene los deberes de impedir y de sancionar las conductas ilícitas y dilatorias en el contexto procesal.

En el caso Donayre, el Tribunal cita los artículos 109 al $112^{18}$, correspondientes al Código ya mencionado, que se refieren a los "Deberes y responsabilidades de las partes, de sus Abogados y de sus apoderados en el proceso". Nuevamente, señala que se ha incurrido en una actitud temeraria, ello con base en el hecho de la presentación de un documento falso, que no ha sido emitido por la entidad que la parte refiere, y que se encuentra, inclusive, legalizado notarialmente. Se entiende que los artículos que cita la sentencia son tomados como una referencia a fin de respaldar la calificación de la conducta en el supuesto de temeridad y/o mala fe.

Ahora bien, es importante en este punto hacer una referencia al artículo 111 del Código Procesal Civil citado anteriormente. En este, se establece que en el supuesto de que se determine la responsabilidad del abogado, esto es, que ha actuado con temeridad o mala fe, deberá remitirse lo actuado a la Presidencia de la Corte Superior, al Ministerio Público y al Colegio de Abogados correspondiente, para que, en ejecución de las investigaciones pertinentes, impongan las sanciones a que pudiera haber lugar. Es en virtud de este artículo que, en las cuatro resoluciones hasta aquí aludidas, se consigna en la parte del fallo que se oficiará a dichos órganos lo resuelto para que procedan de acuerdo a sus atribuciones. Es de resaltar, que en los casos Fernández, Aparcana - Huamán y Donayre, se dispuso oficiar al Colegio de Notarios de Ica para que realice las investigaciones pertinentes y, de ser el caso, sancione al notario que en cada caso certificó los documentos fraudulentos que presentaron las partes junto con sus abogados.

En el caso López, debemos precisar que no se consigna el artículo infringido ni ninguno otro, a pesar de que citar la base normativa es indispensable cuando se trata de la imposición de una sanción ${ }^{19}$. Sin embargo, en tanto se aplicó el artículo 49 del Reglamento del Tribunal Constitucional en dicho caso, es presumible que la infracción se haya producido respecto del artículo 109 del Código Procesal Civil. En particular, sería de aplicación el inciso $4^{20}$ de dicho artículo, por cuanto a través del escrito que se cuestiona, el abogado se expresó faltando el respeto a los magistrados.

Es interesante notar que en los casos existe una consecuencia procesal importante, que se traduce en la declaración de improcedencia de la demanda en todos los casos citados. Con independencia de las conductas en que hayan podido incurrir el abogado y la parte demandante (y que ameritan la sanción respectiva), la declaración de improcedencia tiene su propia justificación, siendo consecuente respecto de los hechos probados en cada caso.

16 Tanto el Tribunal como el Código Procesal Civil hacen uso de ambos términos de manera indistinta y les otorgan las mismas consecuencias jurídicas.

17 "Principios de Iniciativa de Parte y de Conducta Procesal.-

Artículo IV.- (...) Las partes, sus representantes, sus Abogados y, en general, todos los partícipes en el proceso, adecúan su conducta a los deberes de veracidad, probidad, lealtad y buena fe.

El Juez tiene el deber de impedir y sancionar cualquier conducta ilícita o dilatoria."

18 Artículo 109, op. cit.

Artículo 110.- "Las partes, sus Abogados, sus apoderados y los terceros legitimados responden por los perjuicios que causen con sus actuaciones procesales temerarias o de mala fe. Cuando en el proceso aparezca la prueba de tal conducta, el Juez, independientemente de las costas que correspondan, impondrá una multa no menor de cinco ni mayor de veinte Unidades de Referencia Procesal.

Cuando no se pueda identificar al causante de los perjuicios, la responsabilidad será solidaria".

Responsabilidad de los Abogados.-

Artículo 111.- "Además de lo dispuesto en el Artículo 110, cuando el Juez considere que el Abogado actúa o ha actuado con temeridad o mala fe, remitirá copia de las actuaciones respectivas a la Presidencia de la Corte Superior, al Ministerio Público y al Colegio de Abogados correspondiente, para las sanciones a que pudiera haber lugar".

Temeridad o mala fe.-

Artículo 112, op. cit.

19 Principios de legalidad y tipicidad.

20 Artículo 109.- "Son deberes de las partes, Abogados y apoderados.

(...) 4. Guardar el debido respeto al Juez, a las partes y a los auxiliares de justicia”. 
Así, en los cuatro primeros casos parece evidente la justificación de esta consecuencia procesal, por cuanto se presentaron documentos falsificados, sobre los cuales es inadmisible que se sostenga una pretensión. Dichos documentos no representan ningún interés jurídico subyacente que sea merecedor de tutela, por el contrario, son inadecuados para sustentar cualquier pretensión. Por otro lado, en el caso López, la improcedencia se declaró por la inobservancia de las normas procesales en que incurrió la parte demandante y su abogado a lo largo de todo el proceso, inobservancia que es desarrollada en la resolución y que no está relacionada con el motivo de la sanción (frases vejatorias contra los magistrados).

\section{Criterios utilizados por el Tribunal Constitucional al ejercer su potestad para sancionar abogados}

Ante la falta de la regulación de un procedimiento sancionador para casos de mala praxis abogadil ante el Tribunal Constitucional, resulta necesario identificar los criterios utilizados por este órgano al momento de ejercer su potestad sancionadora en esta materia. En las siguientes líneas esbozaremos algunos de ellos.

\subsection{Criterios para la determinación de la existencia de una falta}

A partir de la revisión de los casos seleccionados se ha podido identificar tres criterios utilizados por el Tribunal Constitucional para determinar las actuaciones temerarias o de mala fe al interior del proceso.

El primer criterio es la falta de fundamento jurídico de la pretensión. Este es aplicado en los casos Fernández, Ramírez y Donayre, en tanto en ninguno de ellos la parte demandante cumplió con las reglas para acreditar periodos de aportaciones aplicables a los procesos de amparo. A pesar de ello, los recurrentes solicitaron que les sea otorgada una pensión, incurriendo en total inobservancia de la regulación pertinente. Cabe resaltar que, si bien el mencionado precedente no es referido en el caso Aparcana - Huamán, podemos afirmar que el criterio en cuestión también le fue aplicado. Esto, toda vez que en dicho caso la parte demandante tampoco presentó documentación idónea para acreditar los periodos de aportaciones que requería para acceder a una pensión de jubilación adelantada.

El segundo criterio tiene que ver con la reiteración del acto. Así, respecto de los cuatro primeros casos (Fernández, Aparcana - Huamán, Ramírez, y Donayre), este criterio atiende al hecho de que los documentos falsificados fueron presentados de manera reiterada por la parte demandante, incluso cuando ya habían sido observados en instancias anteriores (caso Ramírez). Pese a su incorrección, fueron ofrecidos como pruebas desde la primera instancia de la vía constitucional hasta llegar a la sede del Tribunal, con la presumible finalidad de intentar sorprender a los miembros de este órgano para obtener un fallo favorable de manera manifiestamente ilegal.

El tercer criterio es el apoyo en la pericia y está presente también en los cuatro primeros casos. Este criterio responde a la potestad del Tribunal de efectuar pruebas de oficio con el fin de esclarecer la veracidad de los documentos ofrecidos en calidad de medios probatorios. Cabe resaltar que no se trata de una facultad general de prueba de oficio, sino, únicamente de una facultad restringida orientada a que el TC verifique que no se está vulnerando alguna garantía constitucional. Es en virtud de ello que el Tribunal ordena actos de verificación, como las solicitudes a la Policía Nacional, por ejemplo, para que, a través de sus órganos de grafotecnia, analice los documentos presentados en el proceso; documentos cuya veracidad resultaba dudosa a prima facie.

\subsection{Criterios para la valoración de los elementos determinantes para la configuración de una falta}

Del análisis de los cuatro primeros casos se pueden identificar dos criterios de valoración de los documentos para establecer su originalidad o falsedad. El primero obedece las máximas de la experiencia, puesto que el Tribunal identifica a simple vista firmas cuyo grado de similitud resulta sospechoso o, de manera lógica, aprecia que las fechas en las cuales son emitidos ciertos documentos no concuerdan con datos que se desprenden más allá del caso (leyes, hechos de la realidad, etc.). Por ejemplo, en relación con los casos, el Tribunal sostiene que dos firmas no pueden ser siempre realizadas de manera idéntica, así hayan sido elaboradas por la misma persona; asimismo, afirma que la personería jurídica consignada en un documento no existía al momento de su redacción, porque fue creada de manera posterior mediante una Ley (hecho que, lógicamente, hace dudar de la legitimidad del documento). 
De otro lado, como segundo criterio se tiene a la recopilación de medios probatorios o criterio de ayuda en la pericia. Así, en los casos Fernández y Aparcana - Huamán, el Tribunal decidió oficiar al Departamento de Grafotecnia de la PNP a fin de que tal entidad emitiese una pericia grafotécnica analizando los documentos de dudosa procedencia. Mediante dichos dictámenes es que finalmente se concluye que las firmas que figuraban en los documentos presentados habían sido objeto de fotomontaje y que, por tanto, estos eran fraudulentos. Algo similar se aprecia respecto del caso Donayre, la falta se determina en base al Informe que solicita el mismo Tribunal y que es remitido por el Seguro Social de Salud del Perú (ESSALUD). En dicho informe se indicó que la constancia presentada por la parte demandante no fue elaborada por dicha entidad.

Con esto se aprecia que, con motivo de esclarecer los hechos, el TC tiene en cierta medida una potestad de la prueba de oficio (en el marco de la valoración la veracidad de los medios probatorios, mas no de una valoración sustantiva de los mismos pues ya fueron evaluados en el proceso ordinario), esto es que puede solicitar la realización de pericias y obtener pruebas para confirmar la veracidad de los documentos presentados a fin de resolver, aunque como ya se ha mencionado, las causales de improcedencia son distintas a las disciplinarias. Llama la atención en este punto que el Tribunal Constitucional deba solicitar este tipo de actuaciones con objeto de esclarecer los hechos, cuando el TC se constituye como la última instancia a nivel nacional. Parece entonces advertirse una falta importante de diligencia de los jueces que resolvieron en las instancias anteriores ${ }^{21}$.

El caso López se aparta de los dos criterios antes mencionados en tanto se sanciona en base a la inclusión plenamente verificable de frases y expresiones en el escrito presentado, que resultan vejatorias y ofensivas respecto de los magistrados. Tales frases son citadas en la resolución y valoradas por el Tribunal Constitucional con base en el uso del lenguaje común y desde una perspectiva objetiva. En ese sentido, la sola presencia de dichas frases justifica la configuración de la falta y posterior imposición de la sanción.

\subsection{Sobre la determinación de la responsabilidad}

En los casos referentes a las falsificaciones, el Tribunal acreditó la existencia de documentos falsos, pero no realizó un análisis de individualización de las responsabilidades y asumió que tanto el abogado como el recurrente son igualmente responsables de la inconducta. A pesar de que el Tribunal Constitucional ha planteado anteriormente que "la sanción, penal o disciplinaria, sólo puede sustentarse en la comprobación de responsabilidad subjetiva del agente infractor de un bien jurídico" (Sentencia 2868-2004-AA, fundamento 21), no parece tener ello en cuenta en los casos que se reseña. El Tribunal, además, apuesta por una aparente responsabilidad solidaria, a la cual hace referencia el artículo 110 del Código Procesal Civil ${ }^{22}$. No obstante, la responsabilidad patrimonial solidaria no es dable a nivel sancionatorio, en donde el principio de culpabilidad, en su vertiente de principio de personalidad de las penas, aplicable también en general para el derecho sancionador, es indispensable si se quiere ser respetuoso con los mandatos constitucionales (BACA ONETO, 2011, p. 15). Así, en los casos objeto de análisis, el Tribunal no analiza las conductas del recurrente y su abogado de forma individual para poder llegar a la convicción de que ambos poseen la misma responsabilidad por la conducta ilícita verificada. Es más, no hace ni siquiera el intento, acción que el artículo 110 del Código Procesal Civil ordena cuando establece que la responsabilidad solidaria será aplicable únicamente ante la imposibilidad de identificar al causante de los perjuicios. La realidad es que los letrados tienen mayor obligación de adecuar sus actos procesales a la legalidad, en tanto deben conocer su Código de Ética y los deberes que el ordenamiento jurídico en general les impone. De ahí la importancia de realizar el análisis de individualización de las conductas.

El Tribunal aplicó este criterio de la responsabilidad solidaria en los casos Donayre, Fernández y López. En los dos últimos impuso tanto al recurrente como al abogado la misma cuantía en la sanción: una multa de 10 URP. En el caso Donayre, en cambio, impuso una única multa de 10 URP a ser pagada de manera solidaria por el recurrente y su abogado.

21 Problema que impide la correcta identificación de la malicia procesal, detectado anteriormente por Giovanni Priori: "las actuaciones de los litigantes que contrarían el principio de la buena fe procesal es el resultado de (...) las consecuencias del actuar de mala fe y con una actitud de los jueces bastante tolerante o poco enérgica frente a esas conductas". (PRIORI POSADA, 2008).

22 Artículo 110.- Responsabilidad patrimonial de las partes, sus Abogados, sus apoderados y los terceros legitimados. Las partes, sus Abogados, sus apoderados y los terceros legitimados responden por los perjuicios que causen con sus actuaciones procesales temerarias o de mala fe. Cuando en el proceso aparezca la prueba de tal conducta, el Juez, independientemente de las costas que correspondan, impondrá una multa no menor de cinco ni mayor de veinte Unidades de Referencia Procesal. Cuando no se pueda identificar al causante de los perjuicios, la responsabilidad será solidaria". (Énfasis agregado). 


\subsection{Sobre la graduación de la sanción}

En los casos reseñados, no ha sido posible identificar una clara graduación de la sanción al imponerse las respectivas multas a los abogados y a los recurrentes. El artículo 49 del Reglamento del Tribunal Constitucional establece un margen de unidades de referencia procesal que comprende desde las 10 URP hasta las 50 URP, pero no establece criterios para su determinación. Por ello, es posible afirmar que la determinación de la sanción se encuentra sujeta a la discrecionalidad del Tribunal.

En las resoluciones revisadas para el presente artículo, se ha impuesto la mínima sanción a los abogados, un monto equivalente a 10 URP, en conformidad con el artículo 49 del mencionado Reglamento. Se entiende así, que la presentación de documentos fraudulentos, incluso en aquellos casos en que existe un intento de certificación por Notario Público, son considerados por el Tribunal como de igual gravedad. Para el caso del escrito presentado con términos vejatorios y ofensivos hacia los Magistrados, el monto de multa nuevamente es el mínimo (de 10 URP), por lo cual, para el Tribunal, se equipara en gravedad a la presentación de documentos fraudulentos, al menos en términos de la sanción.

En cuanto a los casos Aparcana - Huamán y Ramírez, llama la atención el hecho de que se haya establecido una menor multa para los recurrentes, multas ascendentes a 5 y 3 URP respectivamente (con independencia de las multas de 10 URP que le fueron impuestas a cada uno de los abogados). Ello es resaltante, puesto que, en los demás casos, tanto al abogado como al recurrente, les fue impuesto el mismo monto pecuniario (10 URP). Cabe aclarar que en el caso Donayre se estableció una sola multa de 10 URP a ser pagada por el recurrente y su abogado de manera solidaria. No es posible determinar ni se desprende de las resoluciones, la justificación de la menor multa para los recurrentes en estos casos.

Consideramos que el Tribunal podría intentar aplicar algunos criterios que ya se encuentran en otros cuerpos normativos como la gravedad del daño al interés público y/o bien jurídico protegido, la probabilidad de detección de la infracción y el perjuicio económico causado. ${ }^{23} \mathrm{Al}$ aplicar el primer criterio, el Tribunal tendría que argumentar y/o tratar de cuantificar qué tanto se vio perjudicado el correcto desempeño del proceso, en tanto, como señalamos en el siguiente apartado, este sería el bien jurídico protegido por el artículo 109 del Código Procesal Civil. En cuanto al segundo criterio, tendría que evaluar los esfuerzos que tuvo que realizar para detectar la infracción y para corroborarla. Ahí podría incluir, por ejemplo, la necesidad de solicitar pericias grafotécnicas a la PNP o informes a otras instituciones del Estado. Finalmente, en cuanto al criterio referido al perjuicio económico causado, el Tribunal podría tomar en consideración los gastos en términos procesales, tanto económicos como temporales, pues casos como los analizados generan mayor carga procesal de forma innecesaria y de mala de fe. Algunos de los otros criterios, como el de la reincidencia, por ejemplo, podrían ser utilizados como agravantes o atenuantes de la sanción, de cara a incrementar o reducir la multa base impuesta en base al análisis propuesto. Esto, como señalamos, brindaría objetividad y sustento a la actual determinación discrecional de sanciones por parte del TC.

\section{La remisión de oficios a los colegios profesionales para la sanción de los abogados por los mismos hechos}

En los casos expuestos, luego de determinar la infracción que amerita la imposición de las multas por las actuaciones de los abogados que intervienen directa o indirectamente ${ }^{24}$, surge un aspecto problemático sobre la

23 Artículo 248.- Principios de la potestad sancionadora administrativa [...]

3. Razonabilidad.- Las autoridades deben prever que la comisión de la conducta sancionable no resulte más ventajosa para el infractor que cumplir las normas infringidas o asumir la sanción. Sin embargo, las sanciones a ser aplicadas deben ser proporcionales al incumplimiento calificado como infracción, observando los siguientes criterios que se señalan a efectos de su graduación:

a) El beneficio ilícito resultante por la comisión de la infracción;

b) La probabilidad de detección de la infracción;

c) La gravedad del daño al interés público y/o bien jurídico protegido;

d) El perjuicio económico causado;

e) La reincidencia, por la comisión de la misma infracción dentro del plazo de un (1) año desde que quedó firme la resolución que sancionó la primera infracción.

f) Las circunstancias de la comisión de la infracción; y

g) La existencia o no de intencionalidad en la conducta del infractor.

24 Por un lado, se entenderá como intervención directa en los casos que conoce el Tribunal Constitucional a los abogados que actúan en el ejercicio de la defensa de intereses de los particulares; mientras que, por otro lado, se entenderá como intervención indirecta a los funcionarios públicos que realizan documentos, los cuales son utilizados en el proceso. Para los fines de este artículo, quien realiza una intervención indirecta en el proceso son los Notarios Públicos. 
posible inobservancia de la garantía del non bis in idem ${ }^{25}$. Esta situación controversial se plantea debido a que el Tribunal Constitucional remite oficio al Colegio Profesional de los abogados que participan directa $^{26} \mathrm{e}$ indirectamente ${ }^{27}$ en el proceso a fin de que este determine una posible infracción a las normas de ética profesional. Para abordar la referida controversia, corresponde señalar en qué consiste la garantía del non bis in idem y si es aplicable también en el ámbito del derecho disciplinario del abogado.

El non bis in idem, en su ámbito sustantivo, es el derecho a no ser sancionado dos veces por el mismo hecho bajo el mismo fundamento. Según Cassagne, "se trata de un principio de derecho natural que configura una garantía constitucional innominada cuyo sustento se encuentra en el debido proceso legal (...) y en la garantía de razonabilidad de los actos estatales"28 (2017, p. 264). Esta postura ha sido adoptada por nuestro Tribunal Constitucional al señalar que el non bis in idem es un principio que "está implícito en el derecho al debido proceso reconocido por el artículo 139, inciso 3)" (Sentencia 2050-2002-AA-TC, fundamento 18) de dicho cuerpo normativo29 y que en su vertiente material, tiene conexión con los principios de legalidad y proporcionalidad (Sentencia 2050-2002-AA-TC, fundamento 19). Es decir, la falta debe estar tipificada y la sanción debe guardar proporcionalidad respecto de aquella, proporción que se rompe si es sancionada dos veces en base al mismo fundamento.

En su vertiente procesal, el non bis in idem implica que un mismo hecho no pueda ser objeto de dos procesos distintos. Con ello se impide la dualidad de procedimientos en distintas ramas del Derecho (penal y administrativo, por ejemplo) y "el inicio de un nuevo proceso en cada uno de esos órdenes jurídicos (dos procesos administrativos con el mismo objeto, por ejemplo)" (Sentencia 2050-2002-AA-TC, fundamento 19). Ahora bien, en nuestro ordenamiento procesal, se encuentra regulado en el Art. III del Nuevo Código Procesal Penal (NCPP) ${ }^{30}$, estableciendo, de acuerdo con San Martín:

(...) en primer lugar, dos requisitos obvios: unidad de sujeto y de hecho -eadem persona y eadem res-: una misma persona que ha intervenido en la comisión de un hecho concreto (...). En segundo, pese a que la persona y los hechos sean los mismos, se requiere que tengan el mismo fundamento o eadem causa petendi- triple identidad, esto es que vulneren el mismo bien jurídico, sin que sea indispensable la misma calificación jurídica; por tanto, ha de tratarse de normas homogéneas - que el TEDH denomina concurso de normas - que merecen idéntico juicio de reproche (...). (2015, p. 103).

Es decir, para que el non bis in idem sea aplicable se requiere de una triple identidad: mismo sujeto, mismos hechos y mismo fundamento o bien jurídico protegido, siendo este último requisito el decisivo. En vista de que en la controversia planteada nos encontramos ante normas de derecho disciplinario de naturaleza análoga, referidas a la conducencia correcta de los abogados que intervienen en los procesos judiciales (en principio, el mismo fundamento); normas que se encuentran en el Código Procesal Civil y en la regulación que evita el abuso del

25 Existe en la doctrina quienes señalan que existen diferencias entre la denominación de non bis in idem y ne bis in idem. "Se sostiene que entre ambos términos existen diferencias en cuanto a su conceptualización. Se define el ne bis in ídem como: 'Nadie puede ser enjuiciado por los mismos hechos que hayan sido juzgado por resolución firme en un tribunal penal', mientras que la definición de non bis in ídem 'Nadie puede ser juzgado doblemente por un delito'. En ese sentido, se entiende que el ne bis in idem tendría un mayor alcance, pues se refiere de los mismos hechos, mientras tanto en el non bis in ídem los alcances son más restrictivos, pues solo se refiere a delitos. Cabe señalar, que la doctrina y la jurisprudencia nacional e internacional utilizan ambos conceptos de forma indistinta, en razón que sus efectos tienen la misma connotación 'no dos veces de lo mismo'”. (LIZÁRRAGA, 2013)En tanto ambas terminaciones se utilizan de forma indistinta, como plantea Lizárraga (2013), en el presente texto se utilizará non bis in idem.

26 Respecto de los abogados que actúan en el rol de la defensa, a modo de ejemplo, el Tribunal utiliza esta fórmula en el caso Donayre: "Oficiar a la Presidencia de la Corte Superior de Justicia de Ica, al Ilustre Colegio de Abogados de Ica y al fiscal provincial de turno, (...), para que procedan de acuerdo a sus atribuciones".

27 El Tribunal también remite oficio al Colegio de Notarios por su intervención en el proceso al emitir documentos dotados de fe pública, de acuerdo a sus atribuciones. El extremo de la posible inobservancia de la garantía del non bis in idem de los funcionarios públicos en los procesos sancionadores no se desarrollará por exceder los alcances de este informe. Sobre las sanciones impuestas a abogados que ejercen función pública, véase: RAMíREZ, M y ÁLVAREZ, P. El Principio non bis in idem en el derecho disciplinario, en Colombia. lus et Praxis, v. 21, n. 1, p. 345-376, 2015.

28 Esta doctrina española es aplicable al contexto normativo peruano y ha sido reconocida por el mismo TC.

29 "Esta condición de contenido implícito de un derecho expreso, se debe a que, de acuerdo con la IV Disposición Final y Transitoria de la Constitución, los derechos y libertades fundamentales se aplican e interpretan conforme a los tratados sobre derechos humanos en los que el Estado peruano sea parte. Y el derecho al debido proceso se encuentra reconocido en el artículo 8.4 de la Convención Americana de Derechos Humanos" (Sentencia 2050-2002-AA-TC, fundamento 18).

30 Art. III.- "Nadie podrá ser procesado, ni sancionado más de una vez por un mismo hecho, siempre que se trate del mismo sujeto y fundamento. Este principio rige para las sanciones penales y administrativas. El derecho penal tiene preeminencia sobre el derecho administrativo. (...)". (Énfasis agregado). En la misma línea, la Ley de Procedimiento Administrativo General, en el numeral 11 del artículo 248 , establece el non bis in idem. 
proceso -según el artículo 60 del Código de Ética ${ }^{31}$-, seguiría vigente la problemática acerca de si los colegios de abogados pueden sancionar al abogado que, previamente, ha sido sancionado por el Tribunal Constitucional.

Cabe señalar que el marco legal sí habilita al juez, sea en materia civil, penal o constitucional (aplicando la norma supletoriamente), a remitir copias al Colegio de abogados correspondiente en virtud del artículo 111 del Código Procesal Civil cuando considere que se ha actuado con temeridad o mala fe. No obstante, subsiste la controversia sobre el non bis in idem por los criterios esbozados en las líneas precedentes. De acuerdo con Ramírez y Álvarez (2015), para determinar el bien jurídico protegido, primero se debe analizar el tipo legal en concreto y, solo cuando sea necesario, recurrir al cuerpo normativo o, incluso, a la exposición de motivos del mismo con el fin de "desentrañar el espíritu del legislador".

El tipo legal del Código Procesal Civil en que el Tribunal Constitucional basa su actuación, como vimos, es uno genérico referido a los deberes de las partes y sus abogados en el proceso (artículo 109); deberes que pueden ser entendidos en su conjunto como el deber de la buena fe procesal, que a su vez es una manifestación del proceso cooperativo ${ }^{32}$ (SEVILLA, 2016, p. 633). A partir de ello, se puede entender que el bien jurídico protegido sería el adecuado curso del proceso, en relación con la buena conducta del abogado. Por otro lado, el Código de Ética también impone una serie de deberes de conducta a estos profesionales. Su artículo 60 antes mencionado, concretamente prohíbe, por ejemplo, el abuso del proceso y califica la falta a esta norma como una falta a la ética profesional. El bien jurídicamente protegido en este caso también sería el correcto desempeño del proceso. En ese sentido, dos sanciones distintas a un mismo abogado, por los mismos hechos y basadas en tales normas contravendrían el principio de non bis in idem. No obstante lo anterior, para un sector de la doctrina peruana (BOZA; CHOCANO, 2008, p. 237), la controversia aludida se disipa en tanto los jueces y los colegios de abogados perseguirían fines distintos. De acuerdo con Boza y Chocano, la sanción impuesta por los magistrados tiene como fin mantener el orden y el curso adecuado del proceso, toda vez que "el abogado tiene el deber de colaborar con el funcionamiento del sistema de justicia" (2008, p. 237). La sanción de los colegios profesionales, por otro lado, tiene por objeto proteger la confianza de la sociedad en la profesión legal.

El Tribunal Constitucional ha recogido esta última postura en la sentencia recaída en el Expediente N. ${ }^{\circ}$ 3167-2004-AA/TC. En esta establece que la sanción por parte del Poder Judicial y por el Colegio de Abogados de Lima ("CAL") de un mismo hecho, no configura una vulneración al non bis in indem. Esto, debido a que la finalidad de la sanción judicial responde a la reparación del daño, mientras que la sanción del CAL busca "desincentivar conductas que atenten contra el diligente ejercicio de la profesión del abogado" (fundamento 9).

\subsection{La posible inobservancia de otras garantías procesales}

No hay un procedimiento establecido por el Tribunal Constitucional para el tipo de sanciones estudiadas en el presente artículo. Al respecto, llaman la atención dos situaciones que podrían devenir en complejas, dada la ausencia de un procedimiento sancionador propiamente regulado, y a las que nos referiremos de forma breve: la falta de una segunda instancia, ciertos problemas de imparcialidad y una afectación de la proporcionalidad de la sanción.

En cuanto al primer aspecto, el hecho de que las sanciones no sean apelables no parece responder a un adecuado criterio del debido proceso, ni respetar la garantía de la doble instancia para las decisiones que sancionan. Las decisiones en cuestión son gravosas para las partes y los abogados, por lo cual sería importante, y hasta esencial, su revisión, especialmente por cuanto la misma permitiría garantizar el ejercicio del derecho al contradictorio. Dado que el Tribunal es la última instancia, podría plantearse la necesidad de que las sanciones puedan ser revisadas por el Pleno.

Con respecto a la imparcialidad, es problemático el caso López, pues el escrito incluía frases vejatorias y ofensivas hacia los magistrados, siendo ellos mismos quienes resolvieron el caso. Esto, no parece garantizar la imparcialidad que podría requerir una sanción, por lo cual resulta cuestionable.

31 Artículo 60. Abuso del Proceso. "Falta a la ética profesional el abogado que abusa de los medios procesales para obtener beneficios indebidos o procura la dilación innecesaria del proceso".

32 La persecución de la verdad y el desarrollo del proceso es tarea tanto del juez como de las partes, en ese sentido, ambos deben obrar con buena fe procesal (buena fe objetiva) (MITIDIERO, 2009, p. 133). 
Por último, la proporcionalidad de la sanción también es una afectación que amerita un análisis más detallado -que no será abordado en este espacio- en tanto implicaría una propuesta de determinación sobre la graduación de la sanción que diferencie entre abogados y recurrentes al proceso constitucional. Como se ha observado en las líneas precedentes, el TC decide discrecionalmente sobre este aspecto, lo cual debe ser considerado en adelante para que sus sanciones cuenten con legitimidad y de acuerdo con el respeto por las garantías constitucionales necesarias, que son el objeto propio de su actividad.

\section{Conclusiones y algunas recomendaciones}

El Tribunal Constitucional es una institución que tiene la posibilidad de marcar líneas jurisprudenciales sobre la ética profesional. Ya lo ha hecho con respecto al secreto profesional, por ejemplo. Pero eso no es lo único que puede hacer. A través de su propia actividad sancionatoria, tiene la posibilidad de aportar a la forma en que se entiende la ética profesional en nuestro país. No obstante, su actividad, como vimos a lo largo de este artículo, no ha sido acompañada ni de un procedimiento claro ni de una argumentación que se pueda considerar suficiente. Se vuelve necesario una mejora en dicho ámbito para que pueda brindar predictibilidad a los litigantes y guía a la comunidad jurídica en general.

En ese sentido, sería necesario que, por ejemplo, el Tribunal Constitucional, en aras del debido proceso, fundamente adecuadamente la responsabilidad del abogado en la comisión de las faltas que sean demostradas y no continúe imponiendo la misma sanción, y por el mismo monto, al recurrente y al abogado prescindiendo de este análisis. Por otro lado, resultaría de especial relevancia que se implementen mecanismos de coordinación entre el Tribunal y los órganos a los que se hace remisión para que actúen en conformidad con sus atribuciones, especialmente con los Colegios de Abogados, a fin de hacer un seguimiento y verificar que los abogados reciban, de ser el caso, la sanción correspondiente en función de la inconducta en que hayan incurrido.

En el actual contexto político, en el que podemos observar continuamente (mediante audiencias públicas) que varios abogados interponen recursos con alegaciones que son o que ya han sido rechazadas de manera repetida, lo esbozado en estas páginas adquiere mayor relevancia. Corresponde llamar la atención sobre estos hechos con la finalidad de que se observe la corrección de la conducta de la profesión del Derecho, la cual involucra no solo los encargos jurídicos de quienes contratan un servicio profesional, sino también el servicio a nuestra sociedad.

\section{Referencias}

BACA ONETO, V. S. ¿Responsabilidad subjetiva u objetiva en materia sancionadora? una propuesta de respuesta a partir del ordenamiento peruano. Estudios de Derecho administrativo, Montevideo, n. 2, p. 3-24, 2010. Disponible en: https://www.mpfn.gob.pe/escuela/contenido/actividades/docs/2271_responsabilidad_ subjetiva_u_objetiva_en_materia_sancionadora.pdf. Consultado el: 14 mayo 2021.

BOZA, B.; CHOCANO, C. Exposición de motivos del proyecto de código de ética y responsabilidad del profesional en derecho. Lima: THËMIS, 2008.

CASSAGNE, J. C. Derecho administrativo. 2. ed. Lima: Palestra Editores, 2017. t. 2.

CASTILLO, L. El principio de proporcionalidad en la jurisprudencia del Tribunal Constitucional Peruano. Revista Peruana de Derecho Público, Lima, v. 6, n.11, p. 127-151, 2005. Disponible en: https://pirhua.udep.edu.pe/ handle/11042/1908. Consultado el: 14 mayo 2021.

GÓMEZ, H.; ISLA, S.; MEJÍA, G. Apuntes sobre la graduación de sanciones por infracciones a las normas de protección al consumidor. Derecho \& Sociedad, Lima, n. 34, p. 134-146, 2010. Disponible en: https://revistas. pucp.edu.pe/index.php/derechoysociedad/article/view/13336. Consultado el: 17 mayo 2021.

LIZÁRRAGA, V. G. Fundamento del 'ne bis in idem' en la potestad sancionadora de la Administración Pública. In: LIZÁRRAGA, V. G. EI derecho disciplinario en la ddministración pública. Lima: Grijley, 2013. p. 1-18. Disponible en: https://www.mpfn.gob.pe/escuela/contenido/actividades/docs/2271_responsabilidad_subjetiva_u_ objetiva_en_materia_sancionadora.pdf. Consultado el: 10 mayo 2021. 
MITIDIERO, D. Colaboración en el proceso civil: presupuestos sociales, lógicos y éticos. Traducción: J. Monroy. Lima: Communitas, 2010.

PALACIOS, E. A. Temeridad o mala fe. In: CAVANI, R. (coord.). Código procesal civil comentado. Lima: Gaceta Jurídica SA, 2016. p. 654-662.

PERÚ. Tribunal Constitucional. Sentencia Interlocutoria del Tribunal Constitucional Exp. N. ${ }^{\circ}$ 189-2016-PA/ TC. Recorrente: David Guillermo Bolívar Bernales, 11 de septiembre de 2018. Disponible en: https://tc.gob.pe/ jurisprudencia/2018/00189-2016-AA\%20Interlocutoria.pdf. Consultado el: 15 marzo 2021.

PERÚ. Tribunal Constitucional. Sentencia Interlocutoria del Tribunal Constitucional Exp. N. ${ }^{\circ}$ 5030-2015-

PA/TC. Recorrente: Esther Espinoza de Vásquez, 3 de diciembre de 2017. Disponible en: https://tc.gob.pe/ jurisprudencia/2017/05030-2015-AA\%20Interlocutoria.pdf. Consultado el: 15 marzo 2021.

PERÚ. Tribunal Constitucional. Sentencia Interlocutoria del Tribunal Constitucional Exp. N. $^{\circ}$ 4241-2014-PA/ TC. Recorrente: Francisca Enma Ramos Córdova, 12 de noviembre de 2018. Disponible en: https://static.legis. pe/wp-content/uploads/2019/03/04241-2014-AA-Ica-Legis.pe_.pdf. Consultado el: 15 marzo 2021.

PERÚ. Tribunal Constitucional. Auto del Tribunal Constitucional Exp. N. ${ }^{\circ}$ 4021-2014-PA/TC. Recorrente: Francisca Lilia Vásquez Romero, 28 de marzo de 2017. Disponible en: https://img.lpderecho.pe/wp-content/ uploads/2017/08/TC-multa-con-10-URP-por-frases-ofensivas-Legis.pe_.pdf. Consultado el: 15 marzo 2021.

PERÚ. Tribunal Constitucional. Sentencia Interlocutoria del Tribunal Constitucional Exp. N. ${ }^{\circ}$ 7818-2013PA/TC. Recorrente: Nieves Oswaldo Hostia Torrez, 9 de mayo de 2017. Disponible en: https://tc.gob.pe/ jurisprudencia/2017/07818-2013-AA\%20Interlocutoria.pdf. Consultado el: 15 marzo 2021.

PERÚ. Tribunal Constitucional. Sentencia del Tribunal Constitucional Exp. N. ${ }^{\circ}$ 3167-2004-AA/

TC. Recorrente: Luis Sixto Achahui Loayza, 17 de octubre de 2005. Disponible en: https://tc.gob.pe/ jurisprudencia/2005/03167-2004-AA.pdf. Consultado el: 15 marzo 2021.

PERÚ. Tribunal Constitucional. Sentencia del Tribunal Constitucional Exp. N. ${ }^{\circ}$ 2868-2004-AA/TC. Recorrente: José Antonio Álvarez Rojas, 24 de noviembre de 2004. Disponible en: https://www.tc.gob.pe/ jurisprudencia/2005/02868-2004-AA.pdf. Consultado el: 10 mayo 2021.

PERÚ. Tribunal Constitucional. Sentencia del Tribunal Constitucional Exp. N. ${ }^{\circ}$ 2050-2002-AA-TC. Recorrente: Flor de Milagros Ramos Colque a favor de Carlos Israel Ramos Colque, 26 de abril de 2003. Disponible en: https://www.tc.gob.pe/jurisprudencia/2003/02050-2002-AA.html. Consultado el: 10 mayo 2021.

PRIORI, G. El principio de la buena fe procesal, el abuso del proceso y el fraude procesal. Derecho \& Sociedad, Lima, n. 30, p. 325-341, 4 mayo 2008. Disponible en: https://revistas.pucp.edu.pe/index.php/ derechoysociedad/article/view/17419. Consultado el: 10 mayo 2021.

RAMíREZ, M. L.; ÁLVAREZ, P. El principio non bis in idem en el derecho disciplinario del abogado, en Colombia. lus et Praxis, Talca, v. 21, n. 1, p. 345-376, 2015. Disponible en: https://www.scielo.cl/scielo.php?pid=S071800122015000100010\&script=sci_abstract. Consultado el: 14 mayo 2021.

SAN MARTÍN, C. Derecho procesal penal: lecciones. Lima: INPECCP, 2015.

SEVILLA, P. H. Deberes de las partes, abogados y apoderados. In: CAVANI, R. (coord.). Código procesal civil comentado. Lima: Gaceta Jurídica SA, 2016. p. 633-638.

VARGAS, E. El mejor remedio para un mal abogado podría ser... ¿otro abogado?. IUS ET VERITAS, Lima, n. 58, p. 202-224, 16 oct. 2019. Disponible en: https://revistas.pucp.edu.pe/index.php/iusetveritas/article/ view/21285. Consultado el: 09 mayo 2021.

Recebido em: 08.06.2021

Aceito em: 06.08.2021 